\title{
ИССЛЕДОВАНИЕ МЕХАНИЧЕСКИХ СВОЙСТВ, МОРФОЛОГИИ И БИОРАЗЛАГАЕМОСТИ КОМПОЗИЦИЙ ПОЛИЛАКТИДА С ПОЛИСАХАРИДАМИ
}

\author{
(ㄱ) С.3. Роговина ${ }^{1 *}$, К.В. Алексанян ${ }^{1}$, А.Я. Горенберг ${ }^{1}$ Ю.И. Дерябина ${ }^{2}$, Е.П. Исакова ${ }^{2}$, Э.В. Прут ${ }^{1}$, \\ А.А. Берлин ${ }^{I}$ \\ ${ }^{1}$ Институт химической фризики им. Н.Н. Семенова РАН, ул. Косыгина, 4, \\ Москва, 119991 (Россия), e-mail: s.rogovina@mail.ru \\ ${ }^{2}$ Институт биохимии им. А.Н. Баха РАН, Ленинский пр., 33, стр. 2, Москва, \\ 119071 (Россия)
}

В условиях высокотемпературных сдвиговых деформаций в смесителе Брабендер при различных соотношениях компонентов получены смеси полилактида с этилцеллюлозой и хитозаном. Исследования физико-механических свойств композиций показали, что системы обладают высокой жесткостью. Для повышения эластичности в композиции добавляли пластификатор полиэтиленгликоль (ПЭГ) и высокомолекулярный полиолефин полидецен. Оказалось, что полидецен слабо влияет на механические характеристики, в то время как ПЭГ приводит к заметному увеличению значений удлинения при разрыве. Биоразлагаемость полученных композиций исследовали по потере массы образцов после выдерживания в грунте, тестами на грибостойкость и анализом морфологии пленок методом электронной микроскопии после нахождения в грунте. Установлено, что введение третьего компонента (ПЭГ) приводит к увеличению биоразлагаемости композиций.

Ключевые слова: биоразлагаемость, смеси, этилцеллюлоза, хитозан, полилактид, полиэтиленгликоль.

Работа выполнена при финансовой поддержке Российского фонда фундаментальных исследований (грант № 13-03-12070-офи_м)

\section{Введение}

В связи с постоянно возрастающими объемами производства полимеров, приводящих к загрязнению окружающей среды, вопросы их утилизации приобретают все более актуальное значение. Одним из путей решения этой проблемы является создание биоразлагаемых материалов, способных разлагаться на без-

Роговина Светлана Захаровна - ведущий научный сотрудник, доктор химических наук,

e-mail: s.rogovina@mail.ru

Алексанян Кристине Владимировна - старший научный сотрудник, кандидат химических наук, e-mail: aleksanyan.kristine@gmail.com

Горенберг Аркадий Яковлевич - старший научный сотрудник, кандидат химических наук

Дерябина Юлия Ивановна - заведующая лабораторией, кандидат биологических наук

Исакова Елена Павловна - старший научный сотрудник, кандидат биологических наук

Прут Эдуард Вениаминович - заведующий

лабораторией, доктор химических наук, профессор,

e-mail: evprut@chph.ras.ru

Берлин Александр Александрович - директор института, академик PAH, e-mail: berlin@chph.ras.ru вредные для живой и неживой природы вещества, путем смешения синтетических и природных полимеров. Кроме того, использование постоянно воспроизводящихся полимеров природного происхождения (например, полисахаридов) представляет собой замену получаемым из невосполнимых мировых запасов нефти синтетических полимеров. Биоразлагаемые полимерные композиции, позволяющие максимально полно использовать свойства каждого из компонентов, могут быть успешно применены в различных областях, особенно при производстве упаковочных материалов, пленок для пищевых продуктов, а также изделий для кратковременного пользования.

\footnotetext{
* Автор, с которым следует вести переписку.
} 
Ранее нами в условиях сдвиговых деформаций были получены и исследованы композиции природных полисахаридов (крахмала, целлюлозы, хитина) и их производных (этилцеллолозы, хитозана) с полиэтиленом и показано, что их способность к биоразложению зависит как от состава композиции, так и природы входящего в нее полисахарида [1]. Проведение смешения компонентов под действием сдвиговых деформаций обеспечивает повышенную гомогенность образующихся композиций и, таким образом, способствует улучшению их механических свойств.

В настоящее время с целью расширения числа возможных биоразлагаемых систем перспективным направлением представляется разработка таких композиций на основе природных полимеров различных классов. В этой связи данная работа посвящена получению в условиях сдвиговых деформаций и изучению новых биоразлагаемых смесей двух полисахаридов - хитозана и этилцеллюлозы и наиболее используемого биоразлагаемого полиэфира - продукта полимеризации молочной кислоты - полилактида, который благодаря высоким механическим характеристикам, устойчивости к воздействию масел, УФ-излучения способности сохранять форму составляет конкуренцию традиционным полимерам.

По сравнению с другими полиэфирами, получаемыми на основе растительного сырья, благодаря комплексу термических и механических свойств полилактид наиболее перспективен для производства пластиков и волокон с заданными характеристиками, особенно учитывая отсутствие серьезных технологических и экономических проблем при их получении, применении и утилизации.

Полилактиды широко используются для производства волокон, пленок, покрытий, пластиков, а также в биомедицинской практике, однако возможности их применения ограничиваются высокими значениями разрывного напряжения и модуля жесткости. Смешение полилактида с синтетическими и природными полимерами позволяет придавать материалам на его основе новые свойства. Именно этим фактом объясняется большое число работ, посвященное исследованию смесей полилактидов с полимерами различных классов. Так, в [2] изучены смеси полилактида с полибутиленкарбонатом, в [3, 4] - с сополимерами этилена, а в [5] термопластичными полиуретанами. В [6] показано, что смешение полилактида с каучуком приводит к существенному возрастанию величин удлинения при разрыве.

Среди многочисленных смесей на основе полилактида значительный интерес представляют обладающие повышенной биоразлагаемостью его смеси с полисахаридами. Так, композиции полилактид-хитозан используются в медицине для создания каналов, передающих нервные импульсы [7], каркасов для костной ткани [8], а при добавлении монтмориллонита - в качестве носителей для лекарств [9]. Пленки, изготовленные из смесей полилактида и хитозана, обладают повышенной, по сравнению с пленками из чистого хитозана, устойчивостью к воздействию воды, что улучшает их эксплуатационные свойства как упаковочных материалов [10]. Смеси на основе термопластичного эфира целлюлозы (этилцеллюлозы) и полилактида могут быть использованы для формования и литья изделий различного назначения: очковых оправ, рукояток инструментов, зубных щеток и т.д., однако в настоящее время такие смеси не изучены. Для улучшения механических характеристик материалов на основе полилактида к ним часто добавляют пластификаторы. Из многочисленных пластификаторов особый интерес вызывают низкомолекулярные полиэтиленгликоли, введение которых приводит к значительному росту величин разрывного удлинения, повышению пластичности и, как следствие, способствует расширению возможных областей применения получаемых композиций [11-18].

При попадании отходов из полилактидных изделий в окружающую среду происходит их биологическая деструкция с образованием нетоксичных продуктов $\left(\mathrm{CO}_{2}\right.$ и воды). Процесс полного биоразрушения материалов в почве составляет 20-30 месяцев, в то время как в стандартном компосте они распадаются в течение 30-40 дней (для сравнения, целлюлозные материалы при помещении в стандартный компост разрушаются за 15-20 дней). Необходимо отметить, что биоразлагаемость композиций на основе полилактида выше, чем чистого полилактида [19-20].

Целью настоящей работы являлось получение в условиях сдвиговых деформаций биоразлагаемых композиций полилактида с хитозаном и этилцеллюлозой и исследование их механических свойств, морфологии и способности к биоразложению.

\section{Экспериментальная часть}

В работе использовали хитозан (степень дезацетилирования - 0,87, МM - 4,4×105; фирма «Биопрогресс», Россия), этилцеллюлозу (содержание этоксильных групп 46,6\%, динамическая вязкость 57), поли- 
лактид марки Hycail® HM 10111 (плотность 1,24, $\mathrm{T}_{\text {пл. }}$ 150-175 ${ }^{\circ} \mathrm{C}$; HYCAIL, Нидерланды), полиэтиленгликоль (ПЭГ) (ММ - 600), полидецен (ММ - 106).

Смешение хитозана и этилцеллюлозы с полилактидом проводили в смесителе Брабендер, при $160{ }^{\circ} \mathrm{C}$ в течение 10 мин в условиях совместного воздействия давления и сдвиговых деформаций. На этом типе оборудования давление и сдвиговые деформации создаются в закрытой камере в результате вращения двух лопастей. Суть метода основана на разрушении исходных компонентов при создании сложнонапряженного состояния под действием всестороннего сжатия и деформации сдвига.

Для механических испытаний и испытаний на биоразлагаемость и грибостойкость образцы получали в виде пленок толщиной 0,18-0,25 мм прессованием при $160{ }^{\circ} \mathrm{C}$ и давлении 10 МПа в течение 10 мин с последующим охлаждением под давлением со скоростью 15 град/мин.

Механические испытания пленок, вырезанных в форме лопаток с размером рабочей части $35 \times 5$ мм, проводили на разрывной машине «Инстрон 1122» в режиме растяжения при скорости перемещения верхнего траверса 5 мм/мин и комнатной температуре. Из диаграмм напряжение $(\sigma)$ - удлинение $(\varepsilon)$ вычисляли начальный модуль упругости $E$, предел прочности $\sigma_{p}$ и удлинения при разрыве $\varepsilon_{p}$. Результаты усредняли по 10-14 образцам.

Биоразложение полимерных композиций изучали несколькими способами:

а) для исследования биоразложения полимерных композиций, происходящих в природных условиях, образцы помещали в контейнеры с влажной почвой, предназначенной для выращивания растений со значением pH 6-7. Контейнеры выдерживали в термостате при $30^{\circ} \mathrm{C}$ в течение нескольких месяцев. Скорость биодеградации контролировали по потере массы образцов, проводя измерения через определенные промежутки времени;

б) испытания полученных смесей на стойкость к воздействию плесневых грибов проводили согласно ГОСТу 9.049-91. Суть метода заключается в выдерживании материалов, зараженных спорами грибов, в оптимальных для их развития условиях (в водных растворах минеральных солей) с последующей оценкой грибостойкости по степени развития плесневых грибов. Образцы имели форму пластин размером $50 \times 50$ мм. Для испытаний использовали грибы из Всероссийской коллекции микроорганизмов. Концентрация спор различных видов грибов в суспензии составляла 1-2 млн/см ${ }^{3}$. Испытания по определению степени развития грибов проводили в течение 28 суток. Грибостойкость по интенсивности развития грибов на образцах оценивали по шестибалльной шкале;

в) морфологию образцов до и после выдерживания их в почве в течение нескольких месяцев исследовали методом электронной сканирующей микроскопии (СЭМ). Для этого готовили сколы исходных пленок полилактид - хитозан и полилактид - этилцеллюлоза в жидком азоте, а также изучали поверхность пленок. Исследования проводили с использованием сканирующего электронного микроскопа SEM JEOL JSM-70001F (Германия).

\section{Результаты и их обсуждение}

С целью придания новых свойств и расширения возможных областей применения биоразлагаемых материалов на основе полилактида твердофазным смешением компонентов в условиях сдвиговых деформаций в смесителе Брабендер были получены двойные композиции полилактид - этилцеллюлоза и полилактид - хитозан, содержащие 30 и 70 мас.\% полилактида.

Результаты проведенных механических испытаний пленок представлены в таблицах 1 и 2 . Как видно из приведенных данных, добавление этилцеллюлозы и хитозана к полилактиду значительно снижает величины удлинения при разрыве $\varepsilon_{p}$.

При содержании этилцеллюлозы в смеси до 30 мас.\% практически не происходит изменений значений модуля упругости, в то время как его увеличение до 70 мас.\% приводит к значительному уменьшению этой величины. Особенно заметно влияние термопластичной этилцеллюлозы на изменение значений предела прочности $\sigma_{p}$, которое уменьшается при 70 мас.\% содержании этилцеллюлозы по сравнению с чистым полилактидом примерно в 7 раз. Вероятно, наблюдаемый эффект объясняется плохой совместимостью этих полимеров. Добавление 30 мас.\% хитозана незначительно влияет на величины модуля упругости и предела прочности, что, по-видимому, связано с жесткостью самого хитозана (табл. 2).

В общем случае изменение механических характеристик смесей полисахаридов с полилактидом зависит как от состава смеси, так и от природы используемого полисахарида. 
С целью улучшения потребительских характеристик пленок, полученных из смесей полилактид этилцеллюлоза и полилактид - хитозан, в частности для повышения их эластичности, в композиции в качестве третьего компонента были добавлены пластификаторы - олигомер полиэтиленгликоля (ПЭГ) и высокомолекулярный разветвленный полиолефин - полидецен $\left(\mathrm{C}_{10} \mathrm{H}_{20}\right)_{n}$. Тройные смеси полилактид - полисахарид - ПЭГ (полидецен) также были получены в смесителе Брабендер, при этом содержание полисахарида составляло 30 мас.\%, а содержание ПЭГ (полидецена) - 10 мас.\%.

Ожидалось, что полидецен должен способствовать повышению пластичности композиций, однако, как оказалось, его введение слабо влияет на величины механических характеристик пленок, что, повидимому, связано с плохой термодинамической совместимостью полидецена и используемых полисахаридов. В то же время добавление ПЭГ приводит к заметному увеличению значений удлинения. Так, для тройной композиции полилактид - хитозан - ПЭГ (60:20:20 мас.\%) величина удлинения возрастает до $57,5 \%$ по сравнению с исходной двойной системой полилактид - хитозан, для которой величина удлинения составляет 2,5\% (табл. 2). Можно предположить, что последующее снижение величин удлинения при содержании ПЭГ 27 мас.\% связано с фазовым расслоением компонентов. Таким образом, варьируя количество пластификатора, можно получать композиции с различными характеристиками.

Изучение биоразлагаемости пленок, полученных из двойных и тройных смесей, проводили несколькими независимыми методами: закапыванием в грунт и контролируя потерю массы образцов; испытаниями на грибостойкость и исследованием морфологии образцов после нахождения в грунте.

На рисунке 1 приведены кривые потери массы помещенных в почву композиций полилактид - этилцеллюлоза, полилактид - хитозан и их тройных смесей с ПЭГ после их экспонирования в грунте при $30{ }^{\circ} \mathrm{C}$ в течение нескольких месяцев. Как видно из рисунка, характер кривых для всех исследуемых систем практически остается неизменным, а основная потеря массы происходит в течение первых трех месяцев. Визуально на пленках отчетливо видно появление микротрещин и пятен, причем особенно большие изменения были отмечены на образцах, содержащих хитозан. Кроме того, исследованные образцы становятся заметно более хрупкими (рис. 1, вставка).

Результаты испытаний на грибостойкость образцов представлены на рисунках 2 и 3. При рассмотрении пленок, полученных из двойных и тройных композиций на основе этилцеллюлозы, видно, что материал не подвергается глубокой деградации плесневыми грибами, поэтому интенсивность роста плесневых грибов оценена баллом 2 (рис. 2). При рассмотрении образцов при 40-кратном увеличении не видно глубокого прорастания гифа мицелия грибов в толщу полимера; по-видимому, рост происходит на поверхности пленки без изменения структуры полимера (рис. 2, б, г).

Таблица 1. Влияние состава смесей на основе этилцеллюлоза на механические характеристики полученных из них пленок

\begin{tabular}{l|c|c|c|c}
\hline \multicolumn{1}{c|}{ Состав смеси } & $\begin{array}{c}\text { Соотношение } \\
\text { компонентов (мас.\%) }\end{array}$ & $E$, МПа & $\sigma_{p}$, Мпа & $\varepsilon_{p}, \%$ \\
\hline Полилактид & - & $2625 \pm 65$ & $52 \pm 1,0$ & $4,70 \pm 0,05$ \\
Полилактид - этилцеллюлоза & $70: 30$ & $2620 \pm 89,4$ & $32,7 \pm 1,0$ & $1,9 \pm 0,13$ \\
& $30: 70$ & $1650 \pm 96$ & $8,7 \pm 0,6$ & $0,9 \pm 0,1$ \\
Полилактид - этилцеллюлоза - полидецен & $60: 30: 10$ & $1760 \pm 52$ & $29,4 \pm 0,6$ & $2,4 \pm 0,06$ \\
Полилактид - этилцеллюлоза - ПЭГ & $60: 30: 10$ & $1500 \pm 74$ & $12,9 \pm 0,4$ & $1,8 \pm 0,13$ \\
& $60: 20: 20$ & $252 \pm 17$ & $4,9 \pm 0,2$ & $20,1 \pm 1,60$ \\
\hline
\end{tabular}

Таблица 2. Влияние состава смесей на основе хитозан на механические характеристики полученных из них пленок

\begin{tabular}{l|c|c|c}
\hline \multicolumn{1}{c|}{ Состав смеси } & $\begin{array}{c}\text { Соотношения компонентов } \\
(\text { мас. \%) }\end{array}$ & $E$, Мпа & $\sigma_{p}$, Мпа \\
\hline Полилактид & - & $2625 \pm 65$ & $52 \pm 1,0$ \\
Полилактид - хитозан & $70: 30$ & $3110 \pm 90$ & $45,5 \pm 2,2$ \\
Полилактид - хитозан - полидецен & $60: 30: 10$ & $2250 \pm 42$ & $26,2 \pm 0,4$ \\
Полилактид - хитозан - ПЭГ & $60: 30: 10$ & $1370 \pm 61$ & $17,6 \pm 0,3$ \\
& $60: 20: 20$ & $106 \pm 11$ & $8,9 \pm 0,1$ \\
\hline
\end{tabular}




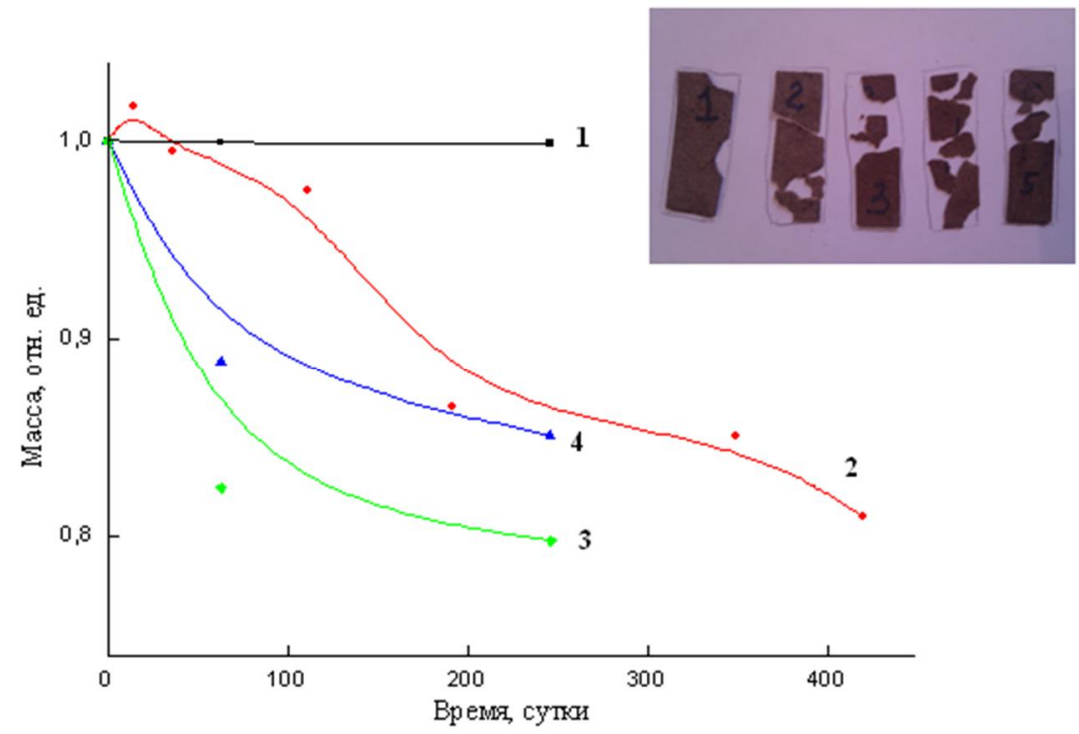

Рис. 1. Кривые потери массы помещенных в почву композиций полилактид - этилцеллюлоза (70 : 30) (1), полилактид - хитозан (70 : 30) (2), полилактид - этилцеллюлоза - ПЭГ (60: 20 : 20) (3), полилактид хитозан - ПЭГ(60: $20: 20)$ (4) после их экспонирования в почве в течение 12 месяцев. Вставка: фотографии пленок смеси полилактид - хитозан (70 : 30) после выдерживания в почве

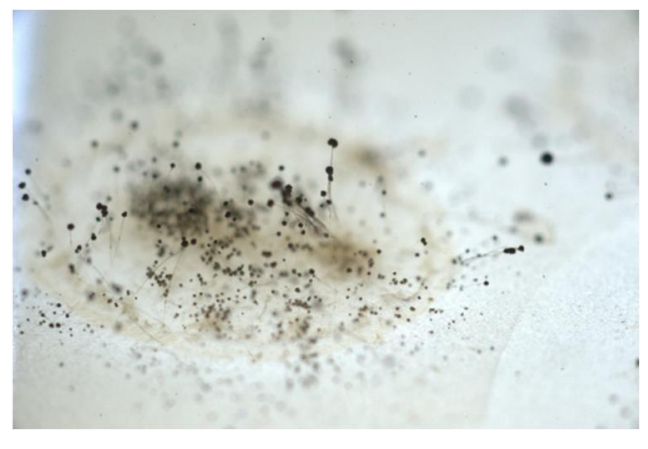

$a$

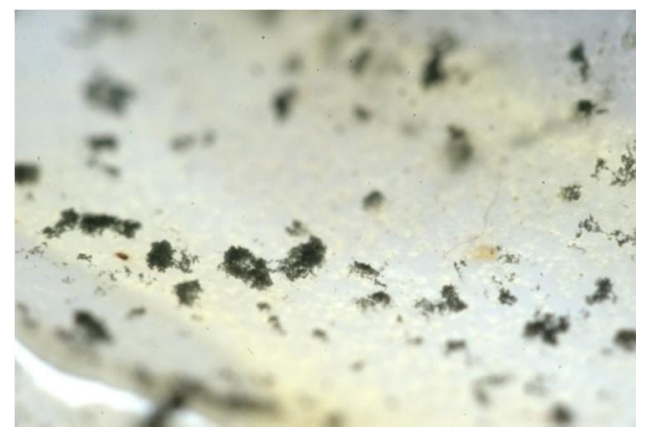

B

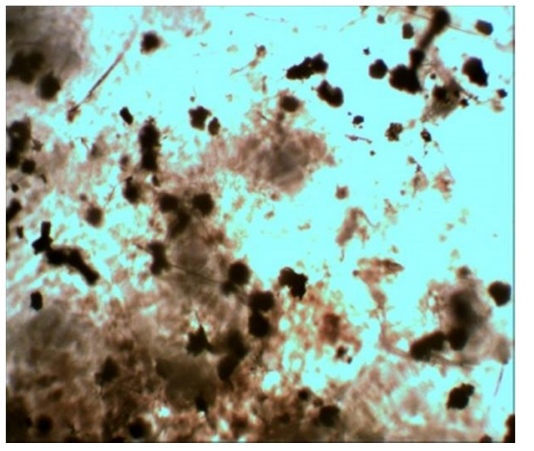

$\sigma$

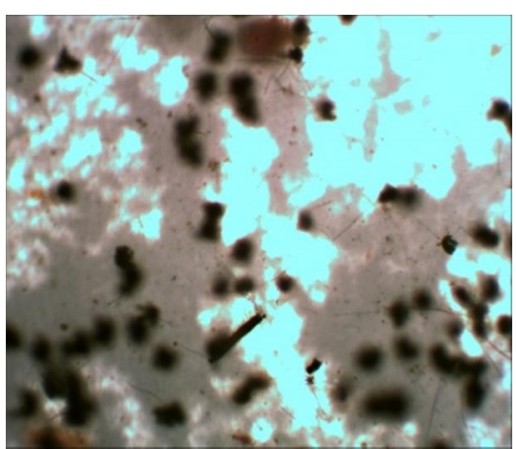

2

Рис. 2. Микрофотографии поверхности пленок из композиций этилцеллюлоза - полилактид (30 : 70) $(a, \sigma)$, этилцеллюлоза - полилактид - ПЭГ (20:60:20) (в, г), инфицированных спорами плесневых грибов в течение 28 дней при различных увеличениях: $\times 15(a, b), \times 40(\sigma, 2)$ 


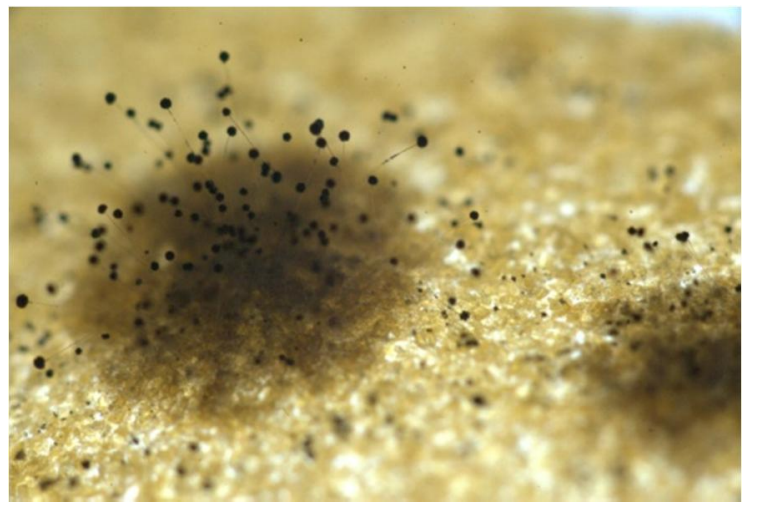

$a$

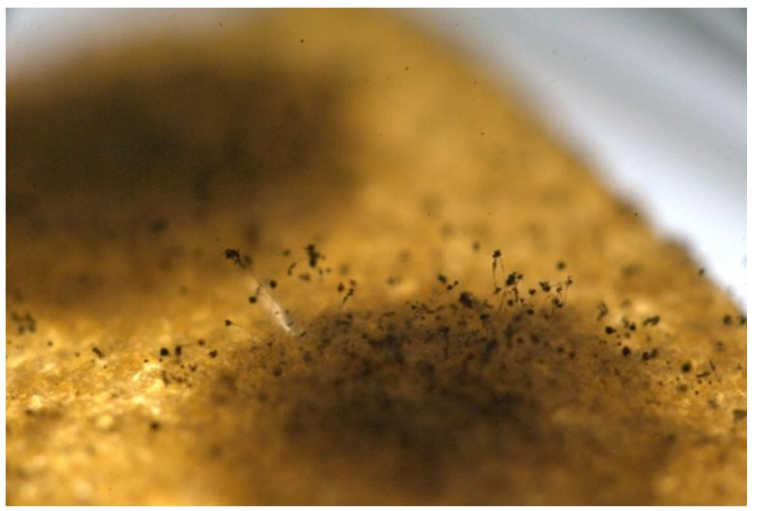

B

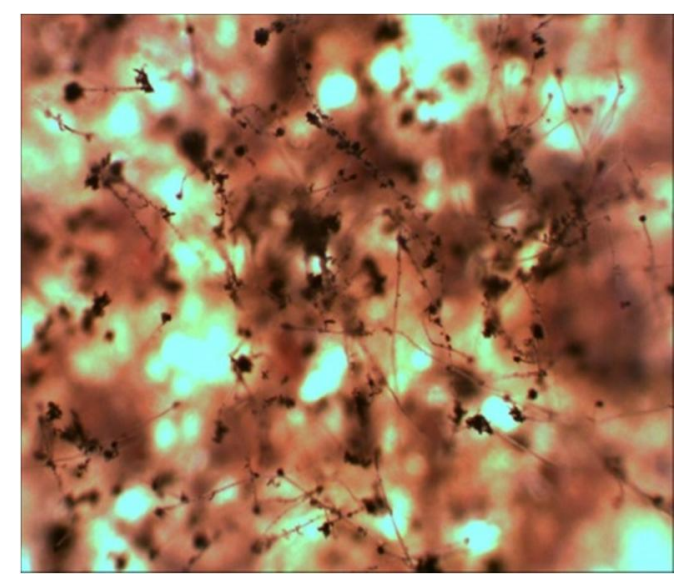

$\sigma$

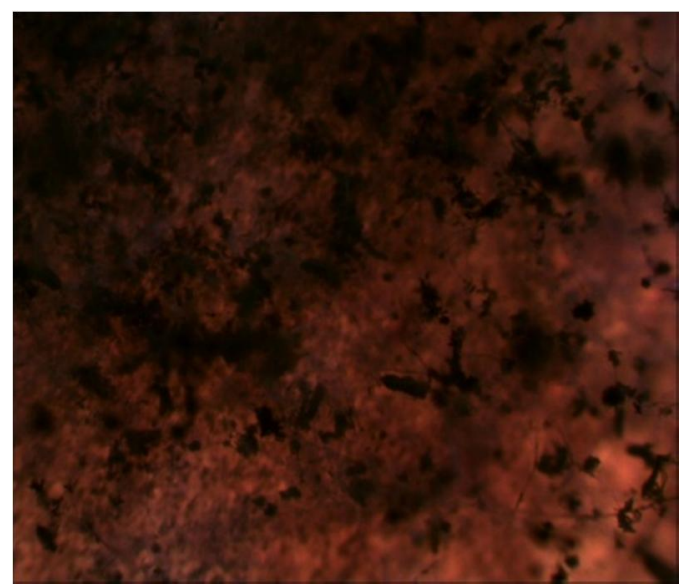

2

Рис. 3. Микрофотографии поверхности пленок из композиций хитозан - полилактид (30: 70) $(a, 6)$, и хитозан - полилактид - ПЭГ (20:60:20) (6, 2), инфицированных спорами плесневых грибов в течение 28 дней при различных увеличениях: $\times 15(a, b), \times 40(6$, г)

На пленках полилактид - хитозан (70 : 30 мас.\%) наблюдается их эффективная деградация плесневыми грибами. При большом увеличении хорошо видно, что имеет место глубокое прорастание гифа мицелия грибов в объем полимера (рис. 3). Интенсивность развития грибов в этом случае была оценена наивысшим баллом 5. Наиболее эффективная деградация плесневыми грибами была отмечена для тройных композиций на основе хитозана. При 40-кратном увеличении отчетливо видно, что имеет место глубокое прорастание гиф мицелия грибов в структуру полимера, которая заметно изменяется в ходе деградации (рис. 3, в). В этом случае интенсивность развития грибов также была оценена на 5. Необходимо отметить, что развитие грибов для всех исследованных систем заметно невооруженным глазом, однако только смеси на основе хитозана проявляют максимальную биоразлагаемость.

Исследование методом сканирующей электронной микроскопии (СЭМ) сколов исходных пленок полилактид - этилцеллюлоза и полилактид - хитозан показало, что исходные структуры этих систем принципиально отличаются друг от друга (рис. 4). Так пленки, содержащие этилцеллюлозу, представляют собой дисперсно-наполненный материал, в то время как на микрофотографиях пленок на основе хитозана отчетливо видны волокна хитозана, распределенные в матрице полилактида. Из рисунка 4, видно, что увеличение содержания пластификатора приводит ке еще более равномерному распределению хитозана в смеси, что объясняет обнаруженное увеличение эластичности пленок.

Поскольку пленки после их нахождения в грунте в течение 5 месяцев обладают повышенной хрупкостью, а их сколы исследованы быть не могут, то с использованием метода СЭМ была изучена поверхность пленок. 
Как видно из рассмотрения микрофотографий, поверхности исходных пленок полилактид-хитозан и полилактид - хитозан - ПЭГ при малом (50-кратном) увеличении покрыты сеткой (рис. 5а, б). При этом же увеличении после выдерживания в почве микротрещины на поверхности пленок становятся глубже и шиpe, особенно для тройных композиций, что приводит, по-видимому, в дальнейшем к растрескиванию и фрагментации материала и свидетельствует о более интенсивном протекании процессов биодеструкции тройных композиций по сравнению с двойными (рис. 5в, г).

При среднем (500-кратном) и особенно большом (2000-кратном) увеличениях (рис. 5д, ж) хорошо видна структура полилактида, напоминающая собой структуру многослойной раковины или губки. При тех же увеличениях в присутствии ПЭГ видно, что распределение компонентов относительно друг друга становится более равномерным (рис. 5е, з).

Несколько иная картина наблюдается для пленок, полученных из композиций полилактидэтилцеллюлоза. На рисунке 6д при среднем (300-кратном) увеличении видно, что структура поверхности пленок представляет собой матрицу, содержащую отдельные волокнообразные элементы. Добавление ПЭГ (рис. 6е) в композицию приводит к появлению микротрещин в пленках, полученных из двойной композиции полилактид - хитозан, т.е. способность к биоразложению композиций на основе этилцеллюлозы в отличие от композиций на основе хитозана отчетливо проявляется в присутствии ПЭГ (рис. 6е). Однако при большом (1000-кратном) увеличении на фотографии двойной композиции отчетливо видна дырка, которая, очевидно, образуется при разрушении полимера в процессе биодеструкции (рис. бж).

Таким образом, данные СЭМ убедительно показывают различия в структуре исследуемых композиций, обусловливающие разные скорости их биоразложения, а также подтверждают результаты, полученные при изучении грибостойкости композиций.

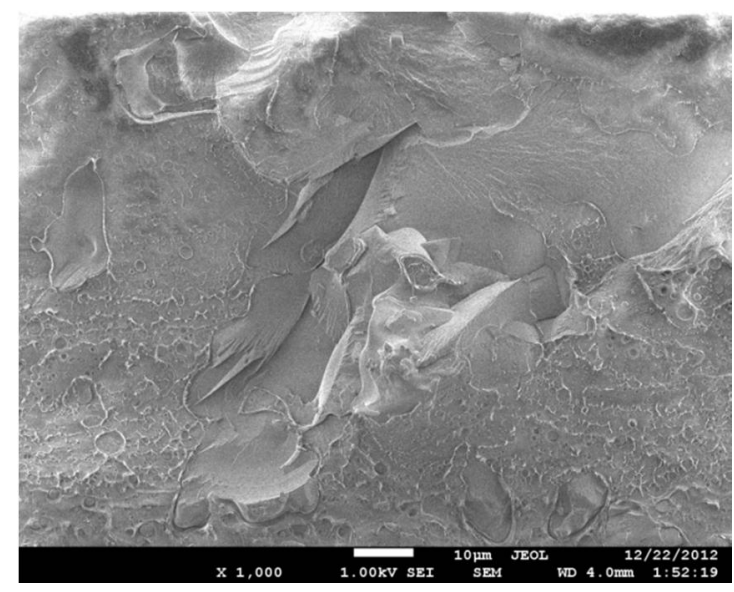

$a$

Рис. 4. Электронные микрофотографии сколов исходных пленок полилактид - этилцеллюлоза и полилактид - хитозан

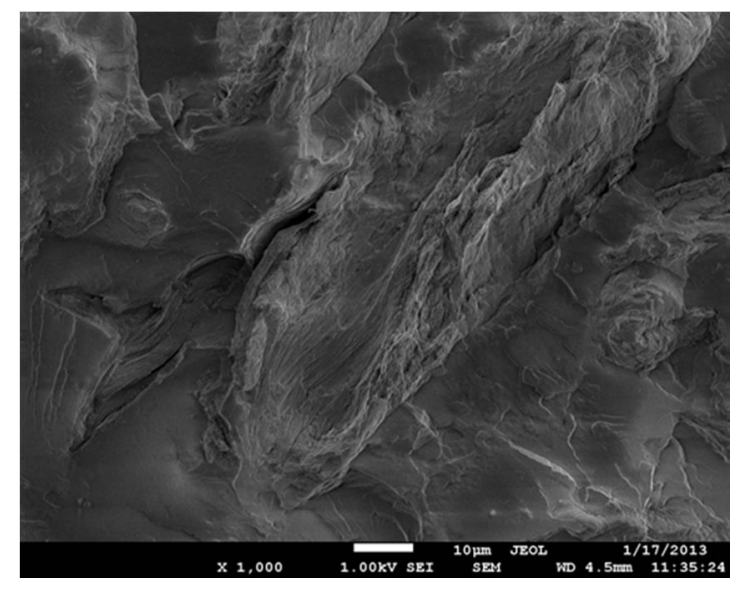

б

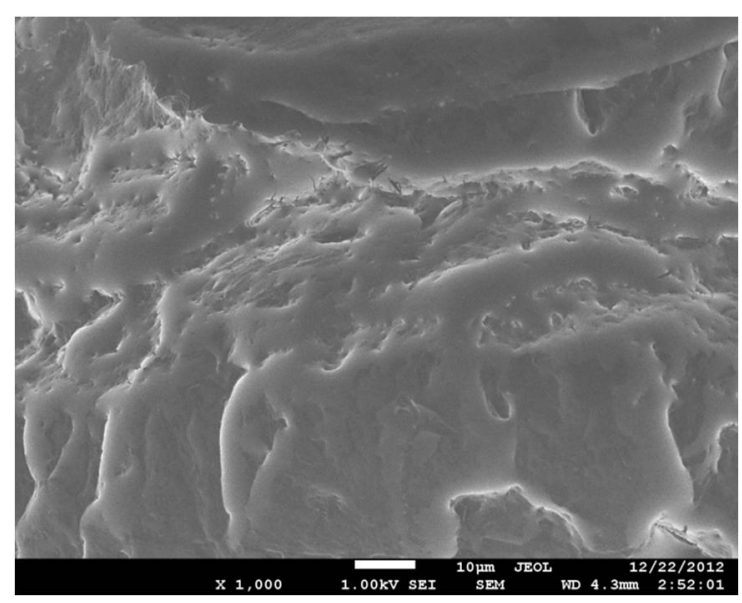

b 


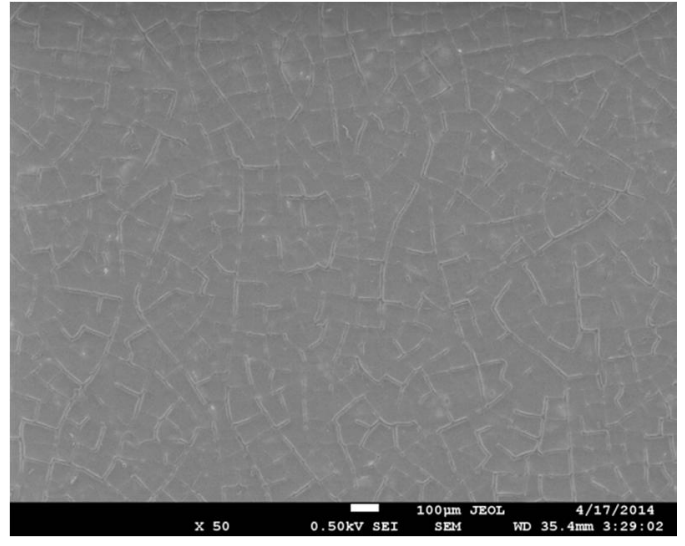

a

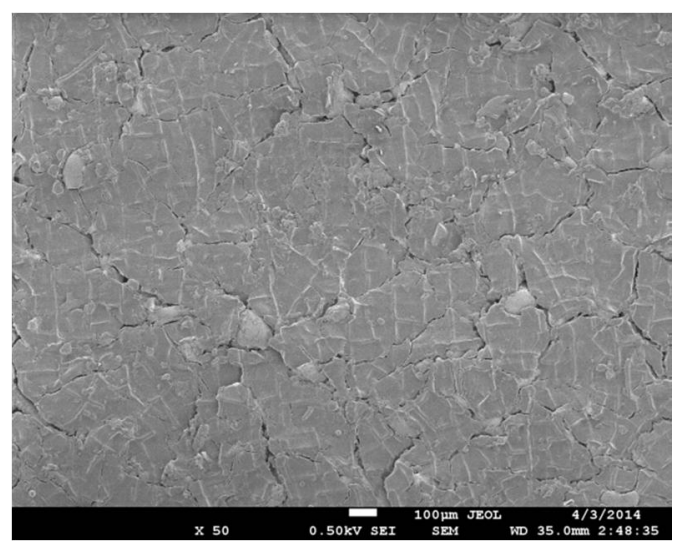

B

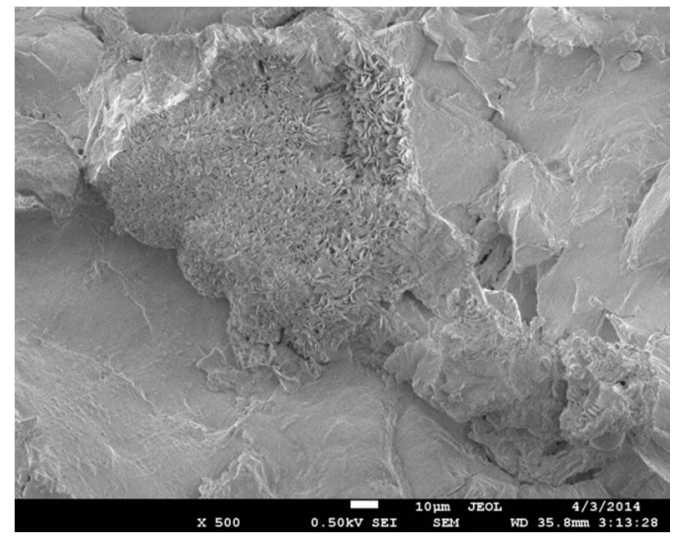

$\partial$

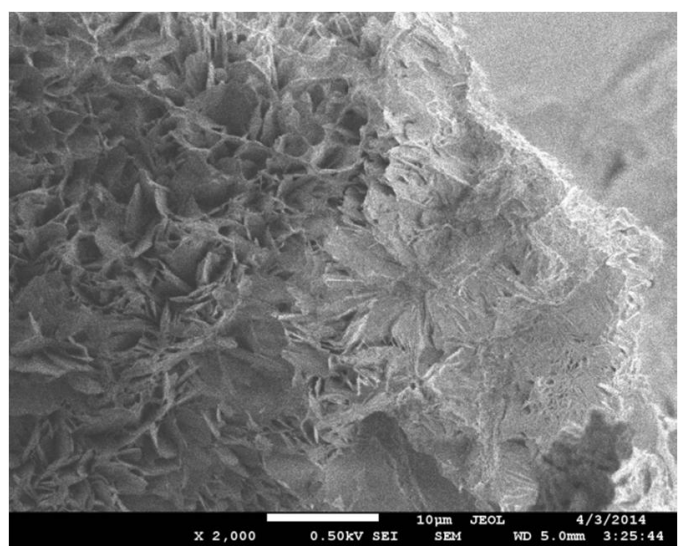

Ж

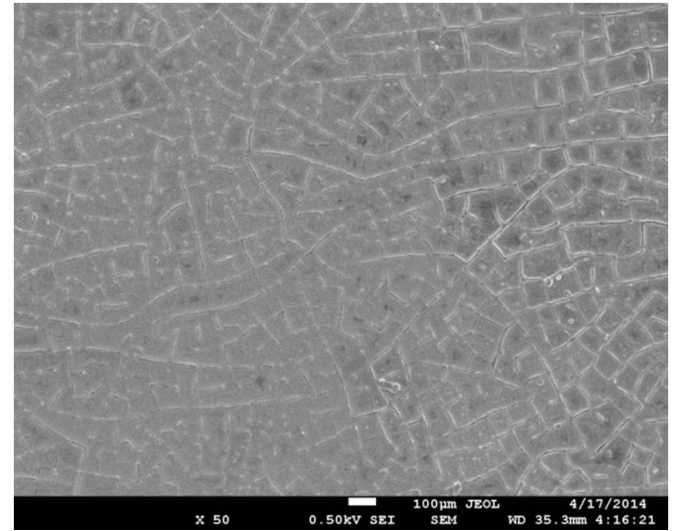

$\sigma$

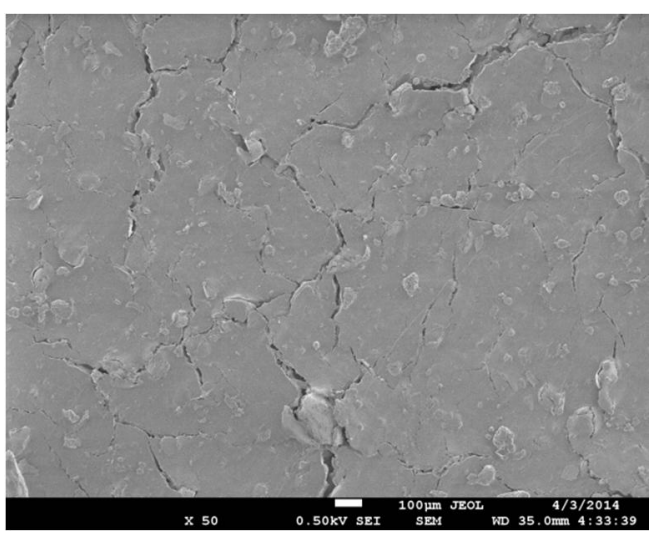

2

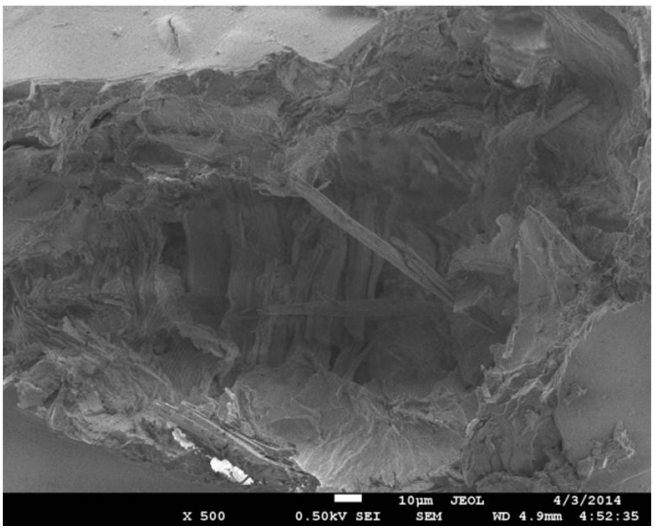

e

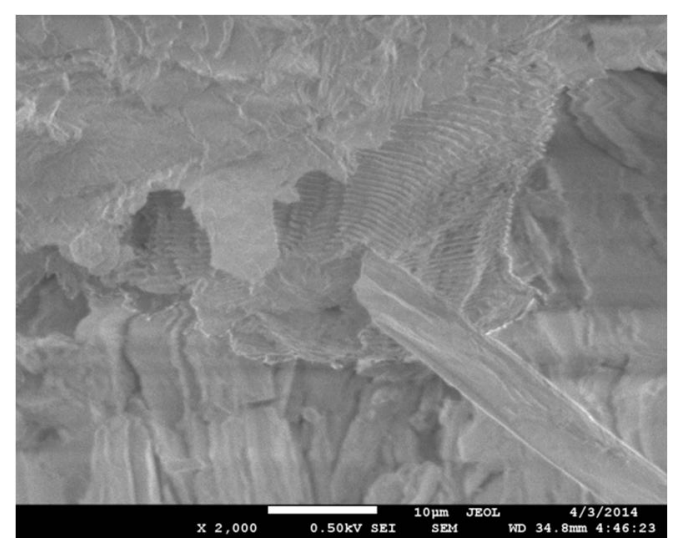

3

Рис. 5. Электронные микрофотографий поверхности исходных пленок хитозан - полилактид $(30: 70)(a, \partial$, ж), хитозан - полилактид - ПЭГ (20:60 : 20) $(\sigma, e, 3)$ до $(a, 6)$ и после $(в-3)$, выдерживания в почве при разных увеличениях: $\times 50(a-2) ; \times 500(\partial, e) ; \times 2000(ж$, з) 

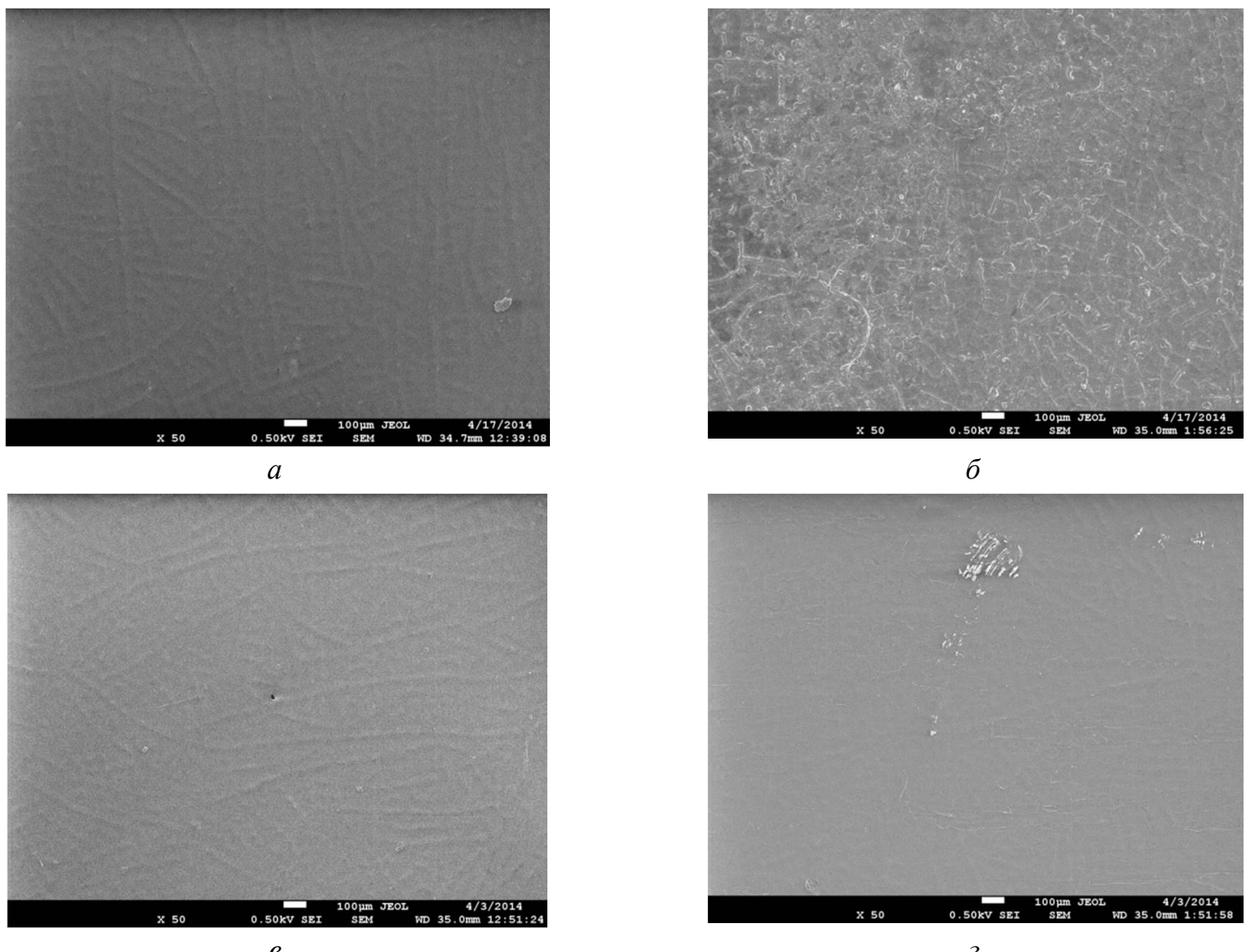

$\sigma$

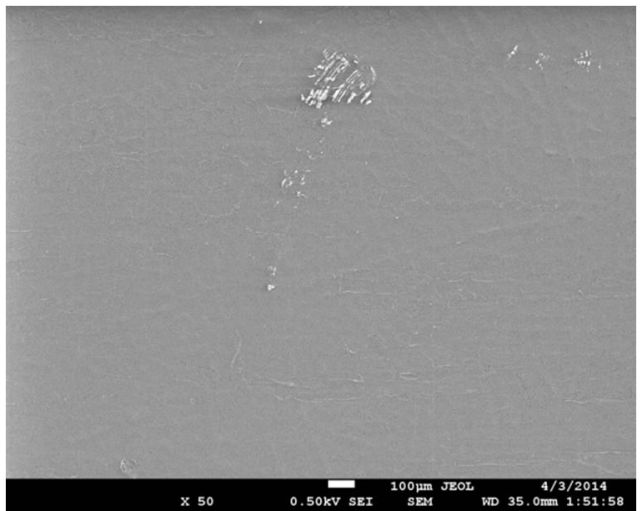

2
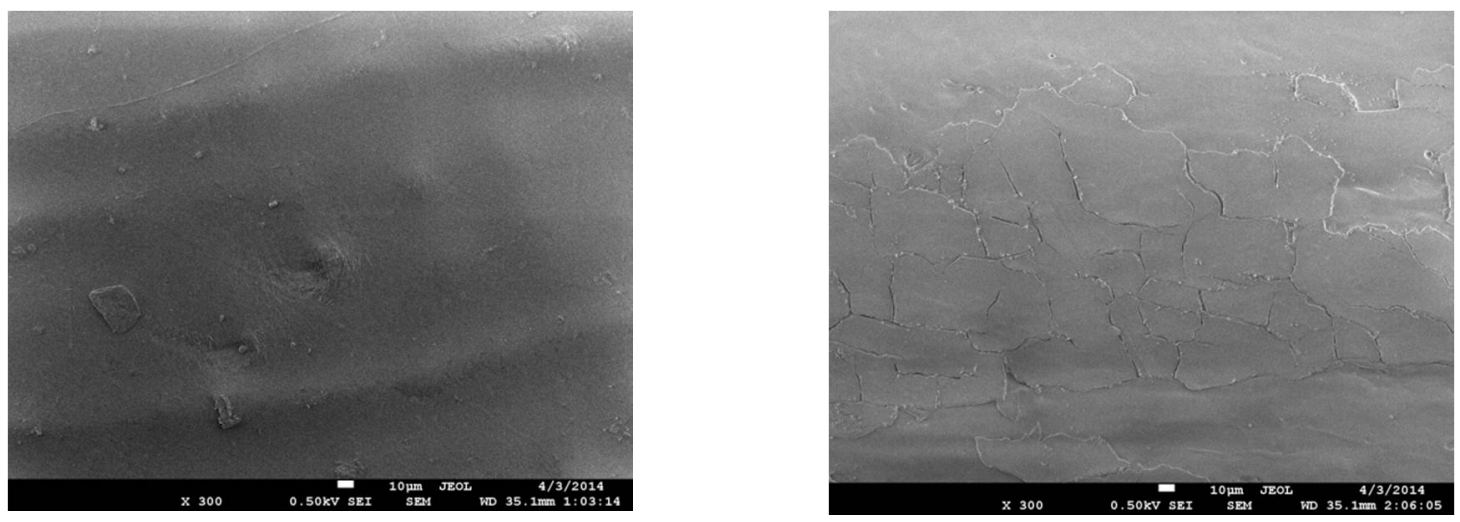

$\partial$

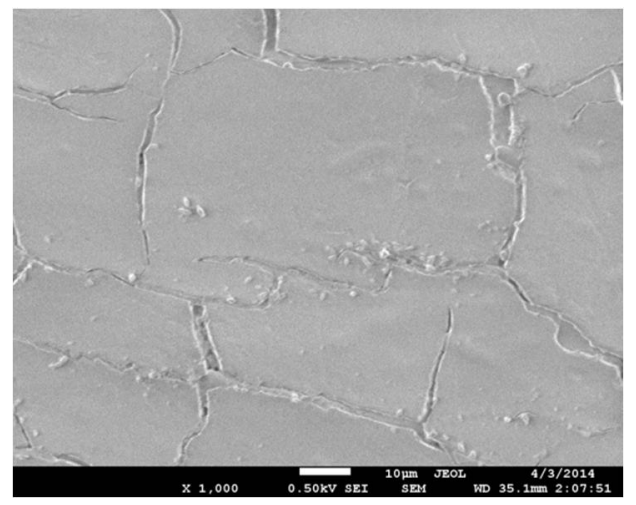

Рис. 6. Электронные микрофотографии поверхности пленок этилцеллюлозы - полилактид $(a, b, \partial$, ж) (30 : 70) и этилцеллюлозы - полилактид - ПЭГ (б, г, e, ж) $(20: 60$ : 20) до (a, б) и после (в-3), выдерживания в почве при разных увеличениях: ×50 $(a-2), \times 300(\partial, e), \times 1000(ж, з)$ 


\section{Выводы}

1. В условиях сдвиговых деформаций твердофазным смешением в смесителе Брабендер получены композиции полилактида с этилцеллюлозой и хитозаном.

2. Измерены механические характеристики композиций и установлено, что добавление пластификатора ПЭГ приводит к увеличению значений удлинения при разрыве.

3. Исследование биоразлагемости композиций по потере массы показало, что добавление ПЭГ приводит к росту биоразлагаемости.

4. При заражении образцов спорами плесневых грибов обнаружено их интенсивное развитие, особенно в присутствии ПЭГ, что является дополнительным доказательством биоразлагаемости полученных композиций.

5. При изучении методом СЭМ морфологии образцов после выдерживания в почве обнаружено образование дефектов в структуре вплоть до образования дырок в присутствии ПЭГ.

\section{Список литературы}

1. Роговина С.З., Алексанян К.В., Новиков Д.Д., Прут Э.В., Ребров А.В. Получение и исследование смесей полиэтилена с природными полисахаридами и их производными // Высокомолекулярные соединения А. 2009. T. 51, №5. C. 813-822.

2. Wang X., Zhuang Y., Dong L. Study of biodegradable polylactide/poly(butylene carbonate) blend // J. Appl. Polym. Sci. 2013. Vol. 127. Pp. 471-477.

3. Anderson K.S., Lim S.H., Hillmyer M.A. Toughening of polylactide by melt blending with linear low-density polyethylene // J. Appl. Polym. Sci. 2003. Vol. 89. Pp. 3757-3768.

4. Feng Y., Hu Y., Yin J., Zhao G., Jiang W. High-impact poly(lactic acid)/poly(ethylene octene) blends prepared by reactive blending // Polym. Eng. Sci. 2013. Vol. 53. Pp. 389-396.

5. Feng F., Ye L. Morphologies and mechanical properties of polylactide/thermoplastic polyurethane elastomer blends // J. Appl. Polym. Sci. 2011. Vol. 119. Pp. 2778-2783.

6. Bitinis N., Verdejo R., Cassagnau P., Lopez-Manchado M.A. Structure and properties of polylactide/natural rubber blends // Mater. Chem. Phys. 2011. Vol. 129. Pp. 823-831.

7. Xie F., Li Q.F., Gu B., Liu K., Shen G.X. In vitro and in vivo evaluation of a biodegradable chitosan-PLA composite peripheral nerve guide conduit material // Microsurgery. 2008. Vol. 27. Pp. 471-479.

8. Li L., Ding S., Zhou C. Preparation and degradation of PLA/chitosan composite materials // J. Appl. Polym. Sci. 2004. Vol. 91. Pp. 274-277.

9. Nanda R., Sasmal A., Nayak P.L. Preparation and characterization of chitosan-polylactide composites blended with Cloisite 30B for control release of the anticancer drug paclitaxel // Carbohydr. Polym. 2011. Vol. 83. Pp. 988-994.

10. Suyatma N.E., Copinet A., Tighzert L., Coma V. Mechanical and barrier properties of biodegradable films made from chitosan and poly (lactic acid) blends // J. Polym. Environ. 2004. Vol. 12, N1. Pp. 1-6.

11. Baiardo M., Frisoni G., Scandola M., Rimelen M., Lips D., Ruffieux K., Wintermantel E. Thermal and mechanical properties of plasticized poly(L-lactic acid) // J. Appl. Polym. Sci. 2003. Vol. 90. Pp. 1731-1738.

12. Chieng B.W., Ibrahim N.A., Yunus W.M.Z.W., Hussein M.Z. Plasticized poly(lactic acid) with low molecular weight poly(ethylene glycol): mechanical, thermal, and morphology properties // J. Appl. Polym. Sci. 2013. Vol. 130. Pp. 4576-4580.

13. Cuenoud M., Bourban P.-E., Plummer C.J.G., Manson J.-A.E. Plasticization of poly-L-lactide for tissue engineering // J. Appl. Polym. Sci. 2011. Vol. 121. Pp. 2078-2088.

14. Gumus S., Ozkoc G., Aytac A. Plasticized and unplasticized PLA/organoclay nanocomposites: short- and long-term thermal properties, morphology, and nonisothermal crystallization behavior // J. Appl. Polym. Sci. 2012. Vol. 123. Pp. 2837-2848.

15. Sungsanit K., Kao N., Bhattacharya S.N. Properties of linear poly(lactic acid)/polyethylene glycol blends // Polym. Eng. Sci. 2012. Vol. 52. Pp. 108-116.

16. Hu Y., Hu Y.S., Topolkaraev V., Hiltner A., Baer E. Crystallization and phase separation in blends of high stereoregular poly(lactide) with poly(ethylene glycol) // Polymer. 2003. Vol. 44. Pp. 5681-5689.

17. Piorkowska E., Kulinski Z., Galeski A., Masirek R. Plasticization of semicrystalline poly(L-lactide) with poly(propylene glycol) // Polymer. 2006. Vol. 47. Pp. 7178-7188.

18. Pluta M. Morphology and properties of polylactide modified by thermal treatment, filling with layered silicates and plasticization // Polymer. 2004. Vol. 45. Pp. 8239-8251.

19. Gupta A.P., Kumar V. New emerging trends in synthetic biodegradable polymers - polylactide: a critique // Eur. Polym. J. 2007. Vol. 43. Pp. 4053-4074.

20. Wu C.-S. Polylactide-based renewable composites from natural products residues by encapsulated film bag: characterization and biodegradability // Carbohydr. Polym. 2012. Vol. 90. Pp. 583-591.

Поступило в редакиию 17 сентября 2014 г.

После переработки 22 декабря 2014 г. 
Rogovina S.Z. ${ }^{1 *}$, Aleksanyan K.V. ${ }^{l}$, Gorenberg A.Ya. ${ }^{l}$, Deryabina Yu.I. ${ }^{2}$, Isakova E.P. ${ }^{2}$, Prut E.V..$^{l}$, Berlin A.A. ${ }^{l}$ INVESTIGATION OF MECHANICAL PROPERTIES, MORPHOLOGY, AND BIODEGRADABILITY OF COMPOSITIONS BASED ON POLYLACTIDE AND POLYSACCHARIDES

${ }^{1}$ Semenov Institute of Chemical Physics, Russian Academy of Sciences, ul. Kosygina 4, Moscow, 119991 (Russia), e-mail: s.rogovina@mail.ru

${ }^{2}$ Bach Institute of Biochemistry, Russian Academy of Sciences, Leninskii pr. 33, build. 2, Moscow, 119071 (Russia)

The blends of polylactide with ethyl cellulose and chitosan are obtained in a Brabender mixer under conditions of high temperature shear deformations at different initials ratios of reagents. The investigation of physicomechanical properties of compositions has shown that systems have high rigidity. To improve the elasticity poly(ethylene glycol) (PEG) and highmolecular polyolefin polydecene are added into compositions. It has turned out that polydecene weakly affects the mechanical characteristics, while PEG leads to noticeable increase in elongation at break. Biodegradability of compositions obtained is investigated by weight loss of samples after holding in soil, tests on fungus resistance, and analysis of film morphology by scanning electron microscopy after holding in soil. It is found that introduction of third component (PEG) leads to increase in composition biodegradability.

Keywords: biodegradability, blend, ethyl cellulosea, chitosan, polylactide, poly(ethylene glycol)

\section{References}

1. Rogovina S.Z., Aleksanjan K.V., Novikov D.D., Prut Je.V., Rebrov A.V. Vysokomolekuljarnye soedinenija A, 2009, vol. 51, no. 5, pp. 813-822. (in Russ.).

2. Wang X., Zhuang Y., Dong L. J. Appl. Polym. Sci. 2013, vol. 127, pp. 471-477.

3. Anderson K.S., Lim S.H., Hillmyer M.A. J. Appl. Polym. Sci. 2003, vol. 89, pp. 3757-3768.

4. Feng Y., Hu Y., Yin J., Zhao G., Jiang W. Polym. Eng. Sci. 2013, vol. 53, pp. 389-396.

5. Feng F., Ye L. J. Appl. Polym. Sci. 2011, vol. 119, pp. 2778-2783.

6. Bitinis N., Verdejo R., Cassagnau P., Lopez-Manchado M.A. Mater. Chem. Phys. 2011, vol. 129, pp. 823-831.

7. Xie F., Li Q.F., Gu B., Liu K., Shen G.X. Microsurgery. 2008, vol. 27, pp. 471-479.

8. $\quad$ Li L., Ding S., Zhou C. J. Appl. Polym. Sci. 2004, vol. 91, pp. 274-277.

9. Nanda R., Sasmal A., Nayak P.L. Carbohydr. Polym. 2011, vol. 83, pp. 988-994.

10. Suyatma N.E., Copinet A., Tighzert L., Coma V. J. Polym. Environ. 2004, vol. 12, no. 1, pp. 1-6.

11. Baiardo M., Frisoni G., Scandola M., Rimelen M., Lips D., Ruffieux K., Wintermantel E. J. Appl. Polym. Sci. 2003, vol. 90, pp. 1731-1738.

12. Chieng B.W., Ibrahim N.A., Yunus W.M.Z.W., Hussein M.Z. J. Appl. Polym. Sci. 2013, vol. 130, pp. 4576-4580.

13. Cuenoud M., Bourban P.-E., Plummer C.J.G., Manson J.-A.E. J. Appl. Polym. Sci. 2011, vol. 121, pp. $2078-2088$.

14. Gumus S., Ozkoc G., Aytac A. J. Appl. Polym. Sci. 2012, vol. 123, pp. 2837-2848.

15. Sungsanit K., Kao N., Bhattacharya S.N. Polym. Eng. Sci. 2012, vol. 52, pp. 108-116.

16. Hu Y., Hu Y.S., Topolkaraev V., Hiltner A., Baer E. Polymer. 2003, vol. 44, pp. 5681-5689.

17. Piorkowska E., Kulinski Z., Galeski A., Masirek R. Polymer. 2006, vol. 47, pp. 7178-7188.

18. Pluta M. Polymer. 2004, vol. 45, pp. 8239-8251.

19. Gupta A.P., Kumar V. Eur. Polym. J. 2007, vol. 43, pp. 4053-4074.

20. Wu C.-S. Carbohydr. Polym. 2012, vol. 90, pp. 583-591. 
